\title{
Reforma y Contrarreforma. El debate teológico en el umbral de la nueva ciencia
}

\author{
Alejandra Velázquez Zaragoza
}

\section{Introducción}

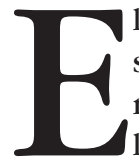

1 enorme impacto de la Reforma protestante, como bien se sabe, no sólo se extendió, en su momento, al terreno religioso; sin duda, la repercusión de ésta -desde su surgimiento en el siglo XVI, hasta la actualidad- ha alcanzado a la política, a la economía, al arte y a la ciencia, entre otros ámbitos de la cultura, incluyendo desde luego al filosófico. En este terreno, entre los siglos XVI y XVII, el debate teológico que diera lugar al cisma de la Iglesia católica, nutrió de manera definitiva la revolución del pensamiento filosófico que condujo a la nueva ciencia.

En efecto, como lo veremos en el primer apartado, la controversia entre reformadores y contrarreformadores (o Reforma católica) se enfocó a la búsqueda de la recta lectura de las Sagradas Escrituras; sin embargo, esta polémica se desplazó de la esfera religiosa a la epistemológica, mediante el replanteamiento del problema del criterio o norma de verdad tanto para la teología como para el saber científico o filosofía natural. Abordaremos este último aspecto en la segunda parte, donde también señalaremos la importante presencia del escepticismo y las respuestas a éste que aportaron importantes ingredientes para la configuración de la filosofía del siglo XVII.

\section{El libro sagrado, en aras de su correcta lectura}

En octubre de 1517, Lutero hizo públicas 95 tesis con el propósito de denunciar la fallida interpretación de las Escrituras por parte de la Iglesia papal. El espíritu del reproche, según se ha insistido, no era el de provocar la división de la Iglesia, sino tan solo el de desterrar sus prácticas abusivas, mediante la supresión de costumbres y prácticas lucrativas impuestas por el clero. La tesis 
37, por ejemplo, señala que: "Todo cristiano, vivo o muerto, incluso sin las cartas de indulgencia, goza de la participación de todos los bienes de Cristo y de la Iglesia concedidos por Dios". ${ }^{1}$ Las tesis 71 y 72 muestran el propósito correctivo, no cismático, de la denuncia: "Sea anatema y maldito quien hable contra la verdad de las indulgencias papales; pero sea bendito quien se preocupe de luchar contra la desvergüenza y la licencia verbal del predicador de las indulgencias". ${ }^{2}$ La iniciativa de Lutero rebasó -como se ha mencionado- su intención inicial, pues además de las conocidas consecuencias de diversa índole que trajo consigo, colocó en el foco de la reflexión el tema del criterio de verdad que habría de sostener la correcta interpretación de la Escritura.

De acuerdo con Lutero, la regla de verdad para el conocimiento religioso es la convicción subjetiva, única vía que ha de conducir a la recta interpretación del libro sagrado. En La cautividad babilónica de la Iglesia, obra de 1520, afirma ofrecer ésta:

[...] a todas las personas piadosas que ansían llegar al conocimiento sincero de la Escritura y al uso correcto de los sacramentos. Como se dice en la primera carta a los Corintios (cap. 2), es un don extraordinario conocer lo que se nos ha dado y el uso que de ello hay que hacer. Apoyados en este discernimiento espiritual, no tendremos necesidad de acudir a interpretaciones falaces. ${ }^{3}$

La sinceridad del discernimiento espiritual, como sustento de la lectura desprejuiciada de los escritos bíblicos, se confirma en su célebre pronunciamiento en la Dieta de Worms (1521):

A menos que se me convenza por testimonio de la Escritura o por razones evidentes - puesto que no creo en el papa ni en los concilios sólo, ya que está claro que se han equivocado con frecuencia y se han contradicho entre ellos mismos-, estoy encadenado por los textos escriturísticos que he citado y mi conciencia es una cautiva de la palabra de Dios. No puedo ni quiero retractarme en nada, porque no es seguro ni honesto actuar contra la propia conciencia. Que Dios me ayude. Amén. ${ }^{4}$

${ }^{1}$ Martín Lutero, "Controversia sobre el valor de las indulgencias. Las 95 Tesis (1517)", en Obras. Ed. de Teófanes Egido. Salamanca, Sígueme, 2001, p. 66.

${ }^{2}$ Ibid., p. 67.

3 Ibid., "La cautividad babilónica de la Iglesia", p. 61. Cursivas mías.

${ }^{4}$ Ibid., "Discurso de Worms", p. 175. 
El dramático escenario planteado por Lutero es descrito por Richard Popkin como la estrategia de "Tender ganchos al cielo", 5 la cual remite a una experiencia que, a la vez que transmite determinadas verdades religiosas, aporta los medios para autentificarlas. Se trata de un proceso que si bien es sostenido por la fuerza de la convicción personal, persigue el logro de una verdad objetiva. Sin embargo, ¿cómo asegurar la rectitud de tal interpretación, a pesar de su sincera intención? O de otro modo: ¿la mera sinceridad puede ser el sustento de la correcta interpretación buscada? ¿Cómo saber, en principio, que la Escritura es la palabra de Dios? ¿Cómo saber que no me engaño? El planteamiento de Lutero a muchos les pareció excesivo, pues conducía a una concepción de verdad que se auto-legitima, fincada en la auto-convicción y que elimina toda posibilidad de duda. ${ }^{6}$

En este asunto, Calvino (1509-1564) intentó aportar una salida para dar solidez a la visión reformadora, al señalar en su Institución de la religión cristiana: "Nosotros, sin discusión alguna, afirmamos que los hombres tienen un cierto sentimiento de la divinidad en sí mismos; y esto, por un instinto natural. Porque, a fin de que nadie se excusase so pretexto de ignorancia, el mismo Dios imprimió en todos un cierto conocimiento de su divinidad [...]"7

Calvino, a diferencia de Lutero, no apela como éste a la mera convicción personal; el "sentimiento de divinidad" al que se refiere, forma parte de la propia naturaleza humana. De este modo, podemos saber que Dios existe porque "naturalmente hay impreso en el corazón de los hombres un cierto sentimiento de la divinidad [...]" En seguida, Calvino da un paso más, pues

5 Richard Popkin, La historia del escepticismo desde Erasmo hasta Spinoza. México, FCE, 1983, pp. 285-286. Para el estudio del impacto del escepticismo en el pensamiento moderno en el periodo comprendido entre 1470 y 1710 , se recomienda R. Popkin, The History of Scepticism. From Savonarola to Bayle. Oxford, Universidad de Oxford, 2003.

${ }^{6} C f$. Ezequiel de Olaso, "El escepticismo antiguo en la génesis y desarrollo de la filosofía moderna”, en Enciclopedia Iberoamericana de Filosofía. Del Renacimiento a la Ilustración I. Ed. de E. de Olaso. Madrid, Trotta/Consejo Superior de Investigaciones Científicas, 1994 , t. 6, p. 139.

${ }^{7}$ Juan Calvino, Institución de la religión cristiana, vol. 1, libro I, cap. III, pp. 7-8. Es importante advertir que la idea de que Dios ha puesto en todos los hombres una "impronta" de su existencia, aparece en algunos pensadores entre los que destaca Descartes, quien la incorpora de manera importante a su argumentación en una de las pruebas de la existencia de Dios en la Tercera meditación: "Y en verdad no hay por qué admirarse de que Dios, al crearme, me haya introducido esa idea [la idea innata de Dios], para que fuera la marca del artífice impresa en su obra [...]" (R. Descartes, Euvres de Descartes. Ed. de Ch. Adam y P. Tannery. Léopold Cerf, 1898/1956. París, J. Vrin, 1996. 11 vols. Edición referida con las siglas AT, luego el número del volumen y la página; $R$. Descartes, Meditaciones acerca de la filosofía primera. Seguida de las objeciones y respuestas. Trad. de Jorge Aurelio Díaz. Bogotá, Universidad Nacional de Colombia, 2009).

${ }^{8}$ Ibid., p. 8. 
no sólo contamos con la impronta divina, también Dios dotó a nuestro intelecto de la capacidad requerida para entender rectamente la Escritura; pues ésta recoge: "en nuestro entendimiento el conocimiento de Dios, que de otra manera sería muy confuso, y deshaciendo la oscuridad, nos muestra muy a las claras al verdadero Dios". 9 Asimismo, la divinidad de la Escritura está garantizada, pues en lo que toca a los profetas y patriarcas: "Dios imprimió en sus corazones tal certidumbre de la doctrina con la que ellos se convencieran y entendieran que aquello que se les había revelado y ellos habían aprendido, había sido manifestado por el mismo Dios". ${ }^{10}$ Así, Calvino postula la impronta de Dios en el hombre, la capacidad para entender "con claridad" las Escrituras y, desde luego, la certeza plena de que éstas son la verdadera palabra de Dios. ${ }^{11}$ Con base en estos postulados, el ginebrino descalifica la autoridad de la Iglesia para establecer criterios:

[...] he aquí la cuestión que suscitan, no sin gran escarnio del Espíritu Santo: ¿Quién nos podrá hacer creer que esta doctrina ha procedido del Espíritu Santo? ¿Quién nos atestiguará que ha permanecido sana y completa hasta nuestro tiempo? ¿Quién nos persuadirá de que este libro debe ser admitido con toda reverencia, y que otro debe ser rechazado, si la Iglesia no da una regla cierta sobre esto? Concluyen, pues, diciendo que de la determinación de la Iglesia depende qué reverencia se deba a las Escrituras, y que ella tiene autoridad para discernir entre los libros canónicos y apócrifos. ${ }^{12}$

Es inaceptable, pues, que las meras determinaciones humanas proporcionen la certeza que se busca en la verdad de la religión:

[...] ¿qué será de las pobres conciencias que buscan una firme certidumbre de la vida eterna, si todas cuantas promesas nos son hechas se apoyan en el solo capricho de los hombres? Cuando oyeren que basta que la Iglesia lo haya determinado así, ¿podrán, por ventura, tranquilizarse con tal respuesta? Por otra parte, iqué ocasión damos a

${ }^{9}$ Ibid., p. 26.

${ }^{10}$ Ibid., p. 27.

${ }^{11}$ En este tema, como en otros, Calvino discute contra la autoridad católica confrontándola con su propia tradición, al retomar la autoridad de san Agustín: "Cuando dirigimos nuestra mirada a las Escrituras, que nos han sido servidas por medio de los hombres, levantamos los ojos a lo alto, de donde nos viene el consuelo. Quienes escribieron las Escrituras eran hombres; su luz era recibida. La verdadera luz era Aquel que ilumina a todo hombre que viene a este mundo" (San Agustín, Obras. Tratados sobre el Evangelio de san Juan (1-35). Madrid, Biblioteca de Autores Cristianos, 1968, t. XIII, p. 75).

${ }^{12}$ J. Calvino, op. cit., vol. 1, libro I, cap. VII, p. 30. 
los infieles de hacer burla y escarnio de nuestra fe, y cuántos la tendrán por sospechosa si se creyese que tiene su autoridad como prestada por el favor de los hombres! $!^{13}$

Sin embargo, para poner en marcha la "institución natural" de la que estamos dotados y que nos permite obtener la certeza buscada, hace falta un elemento activo indispensable: la iluminación, pues sin ella, afirma Calvino, no podemos reconocer a Dios. La evidencia requerida, entonces, ocurre por la iluminación que nos otorga, como un don, el Espíritu Santo: "las cosas recónditas solamente por la revelación del Espíritu le son manifestadas al entendimiento humano, de tal manera que son tenidas por locura cuando el Espíritu de Dios no le ilumina”. ${ }^{14}$ De este modo, se completa la estrategia: no sólo poseemos la naturaleza que nos faculta para acceder con certeza al entendimiento de la Escritura; la actividad divina hace posible la persuasión íntima que nos otorga la garantía completa de nuestro conocimiento religioso. Empero, a pesar de los esfuerzos argumentales de Calvino hay aquí un círculo que debemos notar, ${ }^{15}$ y que no pasó inadvertido por sus críticos: el criterio para reconocer la verdad del conocimiento religioso es la persuasión íntima, cuya garantía de autenticidad es Dios, y ésta queda asegurada por la persuasión íntima.

Por su parte, los contrarreformadores, o si se prefiere denominarlos, los reformadores católicos - para evitar el sentido reactivo del prefijo "contra" - ${ }^{16}$ desarrollaron diversos argumentos en oposición a la visión reformadora,

${ }^{13}$ Idem.

${ }^{14}$ Ibid., p. 90.

${ }^{15}$ Ezequiel de Olaso analiza en forma detallada este círculo argumental. $C f$. E. de Olaso, "El escepticismo antiguo en la génesis y desarrollo de la filosofía moderna", en op. cit., p. 139.

${ }^{16} \mathrm{H}$. Jedin ha analizado la complejidad historiográfica del concepto contrarrefor$m a$, el cual ha conducido a lecturas que enfatizan -si fuera ése el caso- el carácter exclusivamente contestatario y reactivo del movimiento católico ante el protestantismo. Al respecto, este historiador señala que es parcial: "concebir la escisión de la fe sólo como tragedia, y pasar por alto la profundización y activación de la vida religiosa, que fue su consecuencia, la riqueza de valores que se puso de manifiesto en la reforma católica" (Hubert Jedin, Manual de historia de la Iglesia. Barcelona, Herder, 1966, t. 5, 2a. parte, p. 876). En este mismo sentido, García Cárcel pone de relieve la parcialidad que implica la connotación negativa del concepto contrarreforma. Así, en su estudio historiográfico expone que si bien el sentido de dicho concepto, propuesto por Johann Saint Putter en 1776, subrayaba la cancelación de la libertad de pensamiento por la Iglesia católica, es hacia los años treinta del siglo xx que: "comenzó a cuestionarse la malignidad intrínseca de la Contrarreforma reinterpretando literatura y arte barrocos desde presupuestos distintos". Por ello, afirma García Cárcel, Jedin propuso reemplazar el concepto de contrarreforma por el de reforma católica, lo cual fue plenamente aceptado (R. García Cárcel, "De la Reforma protestante a la Reforma católica. Reflexiones sobre una transición”, en Manuscrits, núm. 16, 1998, pp. 39-63). 
entre los que destacan los siguientes, en este caso, expuestos por el paladín del culto visible (católico), Francisco de Sales (1567-1622), en su obra Las controversias (1593):

[...] el absurdo de los absurdos y la más horrible de todas las herejías, es ésta: mientras [los reformadores] sostienen que toda la Iglesia ha errado durante mil años en el entendimiento de la palabra de Dios; Lutero, Zuinglio y Calvino, para asegurarse que ellos entienden claramente la Escritura, han predicado y enseñado que toda la Iglesia visible yerra, porque puede errar. Yo aseguro que Calvino y todos los hombres pueden errar [más aún] si éstos se atreven a seguir [...] las interpretaciones de la Escritura que mejor les place, haciéndolas pasar por la palabra de Dios. [...] Tomo la enseñanza de Calvino, de que todos pueden errar en materia de religión, incluida la Iglesia y digo otro tanto de él [...] si todos pueden errar en el Entendimiento de la Escritura, ¿por qué no ustedes y sus ministros? ${ }^{17}$

En efecto, de acuerdo con Sales, el reproche que los reformadores dirigen al culto visible, es aplicable a ellos mismos, pues son incapaces de explicar, sin incurrir en círculos argumentales, cuál es la garantía de que su lectura de la Escritura es la correcta. Además, ¿qué nos obligaría a preferir esta lectura cuando no hay una sino muchas? Los reformadores, sigue Sales, no nos ofrecen nada al respecto y han atacado la regla de la fe católica mediante objeciones argumentales que deben aplicarse, primero, a ellos mismos. Sales acepta que la lectura del texto que establece la Iglesia puede ser errónea, pero la del bando contrario no tiene por qué correr mejor suerte, pues como lo señala enfáticamente: "Tomo la enseñanza de Calvino y digo lo mismo de él [...]"18

Por otra parte, al considerar el argumento de la persuasión íntima, Sales repara en la dificultad de garantizar su autenticidad, pues si ésta queda encerrada dentro del sujeto, es invisible y también incomunicable; además, ¿cómo podríamos distinguirla, por ejemplo, de la locura? Es interesante que el reclamo de prescindir de un criterio de validez intersubjetiva, es igualmente aplicable para ambos contendientes; como Sales lo admite en el Discurso Xx de Las controversias, del siguiente modo:

[...] veamos qué regla tienen ellos para separar los libros canónicos de todos los demás eclesiásticos, "el testimonio -dicen-, y la persuasión

${ }^{17}$ San Francisco de Sales, CEuvres complètes. Controverses. Traité de l'amour de Dieu. París, Béthune, 1836, t. 4, p. 124.

${ }^{18}$ Idem. 
íntima del Espíritu Santo”. ¡Oh Dios, qué escondrijo, qué niebla, qué noche! No hay nada claro aquí, en este asunto tan grave e importante. Preguntamos cómo podemos conocer los libros canónicos. Nos gustaría tener alguna regla para detectarlos y se nos remite a lo que ocurre en el interior del alma, que nadie ve, nadie conoce, salvo el alma misma y su creador. ${ }^{19}$

En estas condiciones, queda claro que la doctrina de la infalibilidad, ya fuera la personal o la de la Iglesia, quedó seriamente vulnerada. El resultado de la discusión rebasó las intenciones de cada uno de los bandos en disputa, pues si las Escrituras no son ya transparentes para nadie, hay que buscar, entonces, una salida diferente para enfrentarse al escepticismo en la religión, lo cual algunos encontraron en la ruta del fideísmo; es decir, refugiándose en la fe, antes que en la razón. ${ }^{20}$ Pero, mientras tanto, el efecto de la discusión inundó el ambiente intelectual de la época; la conciencia de las dificultades para acceder de manera directa a la Escritura condujo a asumir la inevitabilidad de la interpretación; es decir, el irrecusable acceso mediado al texto, ya fuera por la norma que impone la autoridad y la tradición o por la ineludible comunicación de la persuasión íntima que exige, como antes se menciona, un criterio de validez intersubjetiva. En esta situación, el escepticismo pronto se erigió en el enemigo común a vencer.

\section{El libro de la naturaleza: más allá del escepticismo}

La postura de Lutero ante el escepticismo ilustra el rechazo que éste despertó en la mentalidad de la época. En el curso de una polémica contra Erasmo, Lutero declara incompatibles la fe y el escepticismo, ${ }^{21}$ pues afirma: "No es la

${ }^{19}$ Ibid., p. 50.

${ }^{20}$ He tocado más ampliamente este tema en A. Velázquez, "Conocimiento y creencia. ¿Fideísmo en Francisco de Sales?”, en José Antonio Robles y Laura Benítez, comps., La filosofía natural en los pensadores de la modernidad. México, UNAM, Instituto de Investigaciones Filosóficas, 2004, p. 24: "el nuevo pirronismo sí alcanzó a Sales aunque no en el ropaje del fideísmo. La necesidad de responder satisfactoriamente, desde su profunda fe católica, al desafío de la Reforma, llevó a Sales, malgre lui, a asumir el talante de una nueva época, signada por la transformación radical del estatus del sujeto con respecto a los distintos ámbitos del saber".

${ }^{21}$ Para el lector interesado en la compleja relación entre Lutero y Erasmo se recomienda acudir al esclarecedor estudio de James Atkinson, Lutero y el nacimiento del protestantismo. Madrid, Alianza, 1968. A propósito de las divergencias teológicas entre estos personajes, Atkinson afirma: "La debilidad de la visión teológica de Erasmo estribaba en que su carácter refinado y recto le hizo subestimar la sujeción al pecado que 
señal distintiva de un espíritu cristiano no complacerse en aserciones; por el contrario, un hombre debe complacerse en aserciones o no será cristiano". ${ }^{22}$ La aserción, entendida como adhesión invariable, impide el camino de la duda o el de la mera opinión, condición indispensable para sostenerse y perseverar en la convicción, pues añade: "El Espíritu Santo no es escéptico" ${ }^{23}$ En la visión reformadora, se denuncia que el católico sucumbe ante al escepticismo porque al recurrir a la autoridad o a la tradición, se requiere probar que éstas son el legítimo juez, cosa que no puede probar la Iglesia. En contraparte, la Iglesia acusa a los reformadores de ser escépticos, dado que la convicción subjetiva no puede ser el auténtico juez que se busca. De este modo, nadie quiere ser escéptico; sin embargo, las mutuas acusaciones de escepticismo parecen haber creado las condiciones para su aparición inevitable en el contexto de la modernidad temprana y, por ende, para obligar a tomar postura ante él.

Así, la pretensión de encontrar el juez idóneo, impulsaría la ruta de la expansión del escepticismo, más allá de los confines teológicos, hacia las facultades cognitivas: el razonamiento y los sentidos. De acuerdo con dicha ruta, debemos desconfiar de nuestros propios principios racionales, pues éstos no son fidedignos. Para tener una ciencia auténtica se requieren principios seguros, empero, los principios que han aportado los filósofos -entre los cuales, los matemáticos se consideran los más seguros- sólo son "presuposiciones falsas", como lo hace notar el abate Léonard de Marandé, para quien los principios matemáticos son:

[...] ideas inmateriales por las que se desean medir las cosas materiales. Quienes están dispuestos a emplear principios y conceptos matemáticos para llegar al conocimiento sólo están haciendo más dudosos sus resultados. Las matemáticas son acerca de objetos imaginarios; por tanto, ¿cómo se les puede aplicar a las cosas físicas que no tienen las mismas propiedades? ${ }^{24}$

Nuestros sentidos, sigue Marandé, sólo nos proporcionan información ilusoria o distorsionada. Las ilusiones ópticas nos permiten constatarlo. Por ejemplo, si presionamos el globo ocular veremos chispas y colores que nos mutilaba a los mortales más inferiores y, por tanto, nunca tuvo la doctrina de la Gracia y la Misericordia de Dios que cautivó a un Agustín o a un Lutero o a un Ignacio" (p. 264). También será de utilidad el ya clásico estudio de Marcel Bataillon, Erasmo y el erasmismo. Barcelona, Crítica, 1978. Véase sobre todo, el capítulo 7: "Hacia una definición del erasmismo", donde se profundiza en la proximidad y distancia entre Erasmo y Lutero.

${ }^{22}$ M. Lutero, Aserción, apud E. Olaso, op. cit., p. 139.

${ }^{23}$ Penelhum, 1983, apud E. Olaso, op. cit.

${ }^{24}$ Léonard de Marandé, Jugement des actions humaines. París, 1624, pp. 60-64, apud R. Popkin, op. cit., pp. 159-160. 
muestran la debilidad de nuestros sentidos para distinguir lo verdadero de lo falso. ${ }^{25}$ De esta manera, siguiendo, al parecer, los argumentos escépticos de Sexto Empírico, ${ }^{26}$ defensor del pirronismo antiguo, la actitud de Marandé ilustra el resurgimiento, en la modernidad, del problema del criterio, el cual condujo al mundo intelectual a tomar posición ante el tipo de certidumbre que podría alcanzarse en el conocimiento de la naturaleza.

Una postura se acogió al escepticismo moderado o académico, el cual aceptó la validez de algunos argumentos del pirronismo pero evitando caer en las consecuencias de un escepticismo total. Por ello, Marin Mersenne (15881648) y Pierre de Gassendi (1592-1655), entre otros, asumieron que si bien el conocimiento humano no puede develar la esencia de las cosas -lo cual está reservado a Dios-; sí podemos desarrollar un conocimiento aproximativo, gradual e hipotético del mundo que nos rodea. Tal saber estará fincado en verdades corregibles, a la luz de la práctica experimental y del apoyo de la matemática como instrumento. De este modo, el escepticismo moderado o académico asumió las siguientes premisas: 1. El conocimiento humano es limitado y desprovisto de la posibilidad de alcanzar la esencia o sustancia de las cosas, pero suficiente para cubrir las necesidades de la ciencia humana. De acuerdo con Mersenne, con relación a los fenómenos naturales: "no hace falta pensar que podamos penetrar [en su naturaleza] ni lo que pasa en el interior de ellos, pues [de dichos fenómenos] nuestros sentidos, sin los cuales el entendimiento nada puede conocer, no ven sino lo que es exterior [... "27 2. El conocimiento humano es instrumental y alcanza el estatuto de certeza moral o hipotética el cual corresponde a las leyes naturales, mismas que, carentes de un sostén metafísico, sólo aportan información acerca de cómo difieren nuestras experiencias, en diferentes condiciones y en vista de ciertos propósitos y 3 . La ciencia de la naturaleza ha de regularse metódicamente, mediante el desarrollo del experimentalismo y su sustento matemático.

En suma, los autores que defendieron esta visión, confluyen en la idea de que la ciencia verdadera, asequible al hombre, requiere de la adopción de una actitud de prudencia, sensatez y moderación ante al conocimiento que,

25 Ibid., p. 159.

${ }^{26}$ De acuerdo con Antonio Gallego Cao y Teresa Muñoz Diego, Sexto Empírico desempeñó un papel protagónico en los comienzos de la filosofía moderna, al grado de que Pierre Bayle lo consideró el padre del pensamiento moderno. Introducción al libro: Sexto Empírico, Esbozos pirrónicos. Introd., trad. y notas de A. Gallego Cao y T. Muñoz Diego. Madrid, Gredos, 1993, pp. 7-8.

${ }^{27} \mathrm{M}$. Mersenne, La vérité des sciences. Contre les sceptiques ou pyrrhoniens. Facsímil Neudruck der Ausgabe. París, Stuttgart-Bad Cannstatt, Friedrich Frommann, 1969 p. 212. Para profundizar en el tema, se recomienda el estudio clásico de R. Lenoble, Mersenne ou la naissance du mécanisme. París, J. Vrin, 1943. 
en su perspectiva, sólo ha de conseguirse asumiendo la rectitud de la sana conducta cristiana. ${ }^{28}$

En contraste, otros filósofos, entre los que destaca René Descartes (15961650), consideraron que realmente se podía derrotar al escepticismo edificando la ciencia sobre la base de verdades incorregibles. ${ }^{29}$ De este modo, la ciencia contaría, en su base, con un nivel de conocimientos provistos de certeza absoluta, al cual pertenecen, por ejemplo, las matemáticas y los principios más generales de las ciencias. En un segundo nivel, Descartes colocó los conocimientos hipotéticos, que son los adecuados para explicar los fenómenos naturales, mediante verdades aproximativas. Algunos de los rasgos que caracterizan la ciencia cartesiana son los siguientes: 1. Está conformada por un conjunto de hipótesis que, derivado de una serie reducida de principios o proposiciones metafísicas, se dirige a dar cuenta de la esencia real del mundo. La certeza que poseen estos principios, de carácter metafísico:

[...] es la que tenemos cuando pensamos que no es en modo alguno posible que la cosa sea de otra forma a como la juzgamos. Esta certeza se extiende a todo lo que es demostrado en las matemáticas; digo tal, pues claramente vemos que es imposible que dos y tres sumados sean más o menos que cinco, o bien que un cuadrado no tenga cuatro lados y cosas semejantes. Esta certeza se extiende también al conocimiento que tenemos de que hay cuerpos en el mundo [...]. Asimismo, se extiende a todo cuanto puede ser demostrado, en relación con los cuerpos, en virtud de la matemática o de otros que sean tan ciertos y evidentes [... $]^{30}$

2. En lo que toca al conocimiento de los fenómenos del mundo externo, por ejemplo, al ofrecer una explicación de la génesis del mundo, Descartes

${ }^{28} \mathrm{Cf}$. A. Velázquez, "Marin Mersenne y la alquimia. La visión moderna de un saber neoplatónico”, en L. Benítez, L. Toledo y A. Velázquez, eds., Tras las huellas de Platón y el platonismo en la filosofía moderna. De su simiente griega a la Ilustración. Ciudad de México, unam/Torres y Asociados, 2013, p. 323.

${ }^{29}$ En este sentido, Laura Benítez, en su análisis del tema del escepticismo que se le adscribe a Descartes, señala: "En su velada oposición a la tradición, Descartes hace ver que la filosofía tradicional, en tanto acrítica, lleva al escepticismo, por lo cual resulta indispensable un cambio en el método filosófico. Así, dudar en un primer paso debe despojarnos de un inútil dogmatismo y permitirnos reexaminar el conocimiento con una sana actitud crítica, no para caer en esa duda que no conoce límites, sino en una filosofía construida sobre la certeza y no sobre la probabilidad" (L. Benítez, Descartes y el conocimiento del mundo natural. Ciudad de México, Porrúa, 2004, p. 89).

${ }^{30}$ R. Descartes, Los principios de la filosofía. Introd., trad. y notas de Guillermo Quintás Alonso. Madrid, Alianza Universidad, 1995, pp. 412-413 [AT IX, 324, Princip., 4a. parte, art. 206]. 
asume explícitamente la certeza moral de las hipótesis que constituyen este nivel, es decir, el carácter de estas suposiciones que se presentan: "como adecuadas para explicar todos los fenómenos y sin dedicarse en particular a examinar [su conformidad] a la verdad". ${ }^{31}$ En efecto, afirma, los astrónomos suelen cultivar este género de explicación, pues, en este ámbito, hemos de contentarnos con obtener, del mismo, tan sólo una certeza moral, la cual es: "suficiente para regular nuestras costumbres o tan grande como la que tenemos acerca de las cosas de las que no tenemos costumbre de dudar en relación con la conducta de la vida, aun cuando sepamos que puede ser que, absolutamente hablando, sean falsas". 32

Por lo anterior, es posible afirmar que durante los siglos XVII y XVIII, en los que se desarrolla la nueva ciencia, los filósofos trataron de superar los problemas planteados por las posiciones escépticas de la época, de cara a los cuales elaboraron sus propuestas metodológicas, ya fueran éstas portadoras de verdades absolutas o solamente aproximativas. ${ }^{33}$

\section{Conclusión}

Desde la tradición de los estudios y discusiones de la teología, la imagen y significado de Lutero y la Reforma han sido cambiantes; ${ }^{34}$ para sus contemporáneos fue "el profeta original enviado por Dios"; para la Ilustración, "fue libertador del despotismo moral, defensor de la razón y adversario de la superstición"; para la generación del Sturm und Drang "fue fundador de la unidad alemana por medio de la lengua"; para el siglo XIX, la figura del reformador cobra diferentes sentidos, incluso opuestos: tanto Lutero conservador como Lutero liberal; en el siglo xx fue considerado el "alemán eterno" y en la actualidad, como lo refiere Hans Küng, el apoyo de la documentación e historiografía contemporáneas da un importante giro realista a la figura de este personaje, pues "Fue la investigación histórica de nuestro siglo la que capacitó a la teología evangélica para construir su comprensión de Lutero no sobre una transfiguración idealizadora, sino sobre una investigación". 35

En este contexto, la Reforma luterana, en su riqueza y complejidad, revela el fuerte impacto que ejerció en el desarrollo de la ciencia moderna. La discusión que ésta abrió entre sus defensores y sus detractores dio paso, como

${ }^{31}$ Ibid., p. 128 [AT IX, 108, Princip., 3a. parte, art. 15].

32 Ibid., pp. 411-412 [AT IX, 323, Princip., 4a. parte, art. 205].

${ }^{33}$ Cf. L. Benítez y J. A. Robles, "El camino de las ideas", en op. cit., p. 111.

${ }^{34}$ Cf. Hans Küng, El cristianismo. Esencia e historia. Madrid, Trotta, 2004, pp. 532-533.

${ }^{35}$ Idem. 
se ha señalado, a la búsqueda de un criterio de verdad capaz de dar sustento a las convicciones teológicas en debate. Este panorama alimentó la aparición de la conciencia del carácter inevitable de la interpretación, es decir, de la ineludible mediación entre el sujeto y el texto que aspira a desentrañar. La ruta directa de acceso a éste quedó preñada de irremontables obstáculos, provenientes del escepticismo prevaleciente en el entorno, el cual, a pesar de los esfuerzos de uno y otro bando, se convirtió en el adversario que arribó sin boleto de retorno.

Se ha señalado, asimismo, que el desplazamiento de esa situación al terreno epistemológico motivó la necesidad de tomar posición ante el embate escéptico, resultando así dos caminos diferenciados; por una parte, la senda del escepticismo moderado: es posible el desarrollo de la ciencia aunque ésta no alcance el conocimiento de sustancias; y, por otra, la que encaró la lucha contra el enemigo para derrotarlo y acometer la tarea de fundamentar el conocimiento científico sobre bases inamovibles.

Sin duda, según se ha afirmado, la Reforma luterana y las reacciones y consecuencias ante ésta se nutrieron del clima escéptico que inundó el ambiente. Sin embargo, este panorama entraña una posible paradoja, ¿por qué, en la modernidad filosófica, el escepticismo que, como se ha expuesto, cuestiona la posibilidad del conocimiento, es, a pesar de ello, un importante motor para el desarrollo de la nueva ciencia? Es posible ensayar una respuesta que aspire a disipar la aparente contradicción antes mencionada. En efecto, una época caracterizada por el notable desarrollo científico - en el contexto de trascendentes descubrimientos geográficos, particularmente el del Nuevo Mundo y en la era de la imprenta- puede, ciertamente, alentar el escepticismo por cuanto la abundancia de novedades del saber suscita desconfianza en torno al estatuto epistémico que éstas poseen. Ante la cantidad y diversidad de conocimientos, se preguntarían los modernos, ¿cuál es su estatuto epistémico?, ¿qué tipo de certeza se les ha de conferir?, ¿qué tipo de verdad pueden alcanzar? Para solucionar estas cuestiones, el proyecto filosófico de la modernidad temprana se abocó a la tarea de fundamentar el conocimiento. De ese modo, el escepticismo pudo ser el acicate y el telón de fondo en el que se desarrollaría la ciencia nueva y la labor fundamentadora de ese saber.

Por lo anterior, la Reforma luterana, sus efectos y consecuencias, se presenta como uno de los factores que nutrieron el desarrollo antes mencionado de la ciencia moderna. La manera en que fue posible tal impacto ha sido el objetivo de este texto, que aspira a contribuir al estudio de la relación entre estos relevantes acontecimientos: la Reforma luterana y la nueva ciencia, a partir de los cuales el libro sagrado y el libro de la naturaleza habrían de ser leídos tras el abandono del saber tradicional y de la autoridad, al precio, sin embargo, de someterse a la interpretación y a los ineludibles efectos que ésta conlleva. 